\title{
RELATIONSHIP OF AGE TO OUTCOME AND CLINICOPATHOLOGIC FINDINGS IN MEN SUBMITTED TO RADICAL PROSTATECTOMY
}

\author{
ATHANASE BILLIS, LUIS A. MAGNA, MARIANA M. LIRA, LUCIANA R. MOREIRA, HELIO \\ OKAMURA, ALEXANDRE R. PAZ, RITA C. PERINA, RENATA M. TRIGLIA, UBIRAJARA \\ FERREIRA
}

\section{Department of Anatomic Pathology and Department of Urology, School of Medicine, State University of Campinas, Unicamp, Campinas, Sao Paulo, Brazil}

\begin{abstract}
Objective: It is controversial whether age is associated with higher grade and worse outcome. Some studies have not found age to be related to outcome nor younger age to be associated with better response to therapy.

Materials and methods: The study population consisted of 27 patients aged 55 years or younger and 173 patients 56 years or older submitted to radical prostatectomy. The variables studied were preoperative PSA, time to PSA progression following radical prostatectomy and pathologic findings in surgical specimens: Gleason score, Gleason predominant grade, positive surgical margins, tumor extent, extraprostatic extension (pT3a), and seminal vesicle invasion (pT3b).

Results: Comparing patients aged 55 years or younger and 56 years or older, there was no statistically significant difference for all variables studied: preoperative PSA $(p=0.4417)$, Gleason score $(p=0.3934)$, Gleason predominant grade $(p=0.2653)$, tumor extent $(p=0.1190)$, positive surgical margins $(p=0.8335)$, extraprostatic extension $(p=0.3447)$ and seminal vesicle invasion $(p>0.9999)$. During the study period, 44 patients (22\%) developed PSA progression. No difference was found in the time to biochemical progression between men aged 55 years or younger and 56 years or older.

Conclusions: Our findings suggest that age alone do not influence the biological aggressiveness of prostate cancer.
\end{abstract}

Key words: prostatic neoplasms; prostate-specific antigen; prostatectomy; pathology; age factors Int Braz J Urol. 2005; 31: 534-40

\section{INTRODUCTION}

It is controversial whether prostate cancer in younger men have less favorable outcome than in older men (1). For all men with prostatic carcinoma, there is a suggestion of associated higher grade, and worse outcome with increasing age (2-4). However, the data are conflicting on this issue; other studies have not found age to be related to outcome $(5,6)$ nor have they found a younger age to be associated with a better response to surgery (7).
The purpose of our study is to show possible differences between men 55 years or younger and men older than 55 years as related to preoperative PSA, pathologic findings in the radical prostatectomy specimen and time to biochemical progression following surgery.

\section{MATERIALS AND METHODS}

The study was done on 27 patients aged 55 years or younger and on 173 patients 56 years or older 
submitted to retropubic prostatectomy from January 1997 to July 2004 in our Institution. The variables studied were preoperative PSA and pathologic findings in surgical specimens: Gleason score $(<7$ or $\geq 7$ ), Gleason predominant grade $(<4$ or $4-5)$, positive surgical margins, tumor extent, extraprostatic extension (pT3a), and seminal vesicle invasion (pT3b). Time to biochemical progression following surgery was studied comparing the groups.

The surgical specimen previously fixed was weighed, measured and the entire surface inked. The bladder neck and apical margins were amputated. From each cone-shaped amputated margin, 8 fragments were processed through perpendicular sections relative to the margins. The rest of the prostate was serially cut in transverse sections at 3 to $5 \mathrm{~mm}$ intervals.

Blocks were embedded in paraffin, cut at $6 \mu \mathrm{m}$, and one section from each block was stained with hematoxylin and eosin. Presence of adenocarcinoma was diagnosed according to Mostofi \& Price criteria (8). The diagnosis was based on invasion or architectural disturbance. Histological grading was performed according to the Gleason system (9). Prostatic carcinomas with final Gleason score $<7$ were considered low-intermediate grade; and, with final score $\geq 7$ considered high-grade (10). Tumors were also subdivided into 2 groups: with primary grade $<4$ and with primary grade 4 or 5 . Extraprostatic extension was diagnosed according to Bostwick \& Montironi (11), whenever cancer was found in adipose tissue, and corresponded to pT3a in the 2002 TNM staging system (12). Seminal vesicle invasion was defined as an invasion of the muscular wall, as described by Epstein et al. (13), corresponding to pT3b in the 2002 TNM staging system.

Tumor extent was estimated by use of a pointcount method (14). Drawn on a sheet of paper, each quadrant of the whole mount sections contained 8 equidistant points. During the microscopic examination of the slides, the tumor area was drawn on the correspondent quadrant seen on the paper. At the end of the examination, the amount of positive points represented an estimate of the tumor extent.

Biochemical progression was defined as PSA $\geq 0.5 \mathrm{ng} / \mathrm{mL}$. During the study period, 44 pa- tients $(22 \%)$ developed a biochemical progression. The mean and median follow-up for these patients were 19.77 and 15 months, respectively (range 3 to 84 months).

The data were analyzed using the MannWhitney test for comparison of independent samples and Fisher's exact test for evaluating differences between proportions. Time to PSA progression was studied using the Kaplan-Meier product-limit analysis; the comparison between the groups was done using the log-rank test. The mean and median periods among 133 men without biochemical progression (censored) were 25.94 and 21 months, respectively (range 3 to 81 months); 23 patients without tests for PSA level following radical prostatectomy were excluded. P value $<0.05$ was considered statistically significant. All statistical analyses were performed using Statistical 5.5 software (StatSoft, Inc., Tulsa, OK, USA).

\section{RESULTS}

Table-1 summarizes the results. There was no statistically significant differences between younger and older patients with prostate cancer related to preoperative PSA ( $p=0.4417)$, Gleason score $(p=0.3934)$, Gleason predominant grade $(p=0.2653)$, tumor extent $(\mathrm{p}=0.1190)$, positive surgical margins $(p=0.8335)$, extraprostatic extension $(p=0.3447)$ and seminal vesicle invasion ( $p>0.9999)$.

Figure-1 shows the time to PSA progression using the Kaplan-Meier product-limit analysis. The log-rank test did not show any statistical difference between the groups $(\mathrm{p}=0.4683)$.

\section{COMMENTS}

Carcinoma of the prostate is distinctly uncommon in men under 50 , accounting for $1 \%$ of all patients with clinically detected prostate cancer and is exceedingly rare in children and adolescents, with only a few reported cases (1). Hereditary prostate cancer accounts for $9 \%$ of all cases of carcinoma of the prostate but $43 \%$ of cases diagnosed before age 55 (15).

The influence of age in the biological aggressiveness of prostate cancer is controversial. Carter et 


\section{Cumulative Proportion Surviving (Kaplan-Meier)}

- Complete + Censored

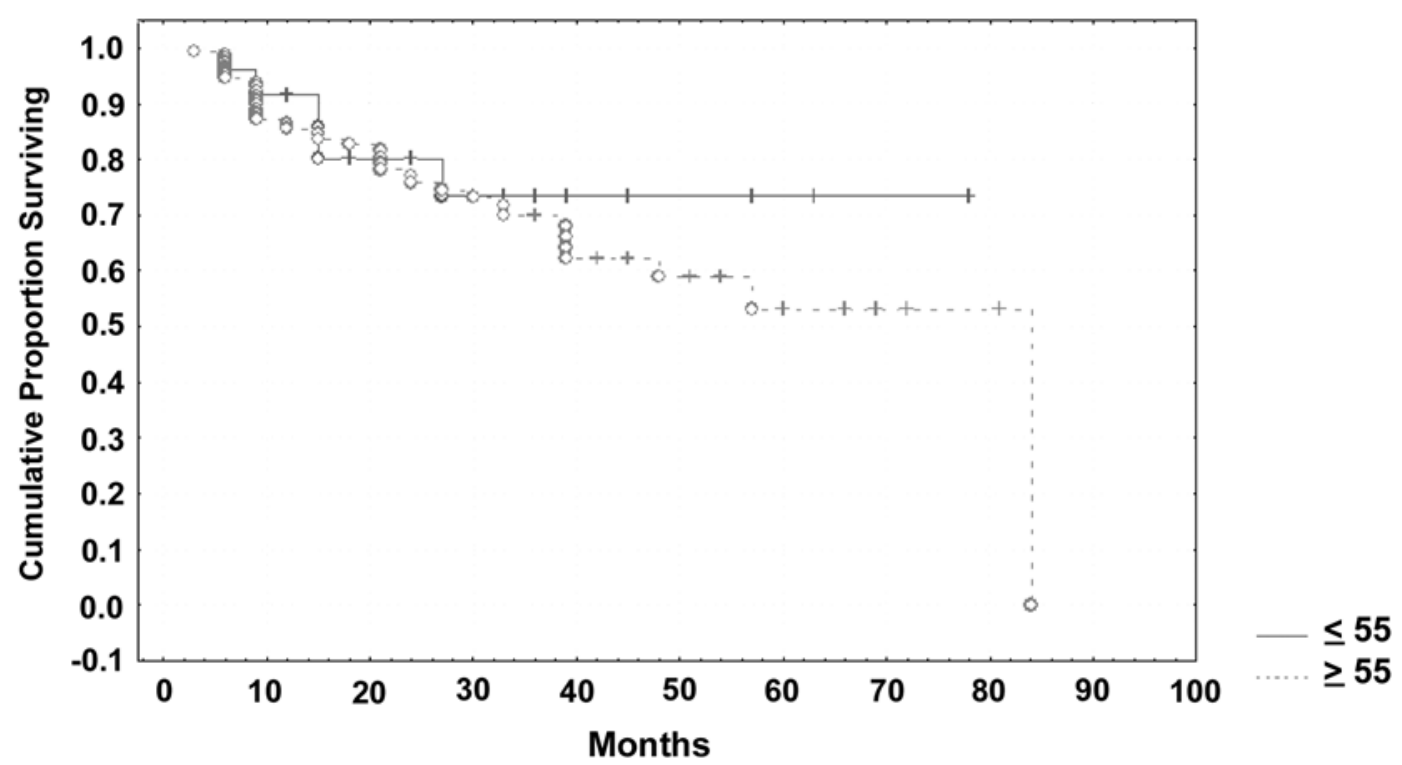

Figure 1 - Time to PSA progression postoperatively according to age $(\leq 55$ year-old or $>55$ year-old). Kaplan-Meier product-limit analysis (log-rank: $P=0.4683$ ).

al. (2), Herold et al. (3) and Partin et al. (4) suggest that prostatic carcinoma is higher grade and has worse outcome with increasing age. However, the data are conflicting on this issue. Bauer et al. (5) and Catalona $\&$ Smith (6) have not found age to be related to outcome. Smith et al. (7) suggest that patients aged 50 years or younger have a more favorable disease-free outcome compared to older men.

The findings of our study showed that younger and older men do not have statistically significant differences as related to preoperative PSA, pathologic findings in the surgical specimen, and time to biochemical progression following radical prostatectomy.

In our study $27(13.5 \%)$ and $173(86.5 \%)$ were $\leq 55$ year-old and $>55$ year-old, respectively. This proportion is quite similar to Smith et al. (7); of a total of 477 men studied, $79(16.56 \%)$ and 398 $(83.43 \%)$ were $\leq 50$ year-old and $>50$ year-old, respectively. There was no statistical difference related to preoperative PSA in our study. It is noteworthy that a comparative study by Carter et al. (2) within age groups and within PSA groups revealed that the probability of curable cancer was more closely associated with age than preoperative serum PSA level.

There was no statistically significant difference between young and older patients considering pathologic findings in the surgical specimen: Gleason score, Gleason predominant grade, tumor extent, positive surgical margins, extraprostatic extension and seminal vesicle invasion. It is noteworthy a much higher proportion (not statistically significant) of predominant grade 4 or 5 in older patients. This may be due to the lower number of young patients in the series. In both younger and older patients, there was approximately $40 \%$ of positive surgical margins and not organ-confined tumor (pT3a and pT3b). This finding may explain the relatively short mean and median period of PSA progression (19.77 and 15 months, respectively).

The definition of the serum PSA level for biochemical progression is controversial and varies from $0.2 \mathrm{ng} / \mathrm{mL}$ to $0.6 \mathrm{ng} / \mathrm{mL}$ in the literature (16-20). In our institution, this level is defined as $0.5 \mathrm{ng} / \mathrm{mL}$. The 
Table 1 - Clinicopathologic features of men undergoing radical prostatectomy, by age.

\begin{tabular}{|c|c|c|c|}
\hline Characteristics & $\leq 55$ year-old $(\%)$ & > 55 year-old $(\%)$ & p Value \\
\hline Number of patients & $27(13.50)$ & $173(86.50)$ & \\
\hline \multicolumn{4}{|l|}{ Preoperative PSA (ng/mL) } \\
\hline Mean \pm SD & $9.19 \pm 6.10$ & $10.66 \pm 7.25$ & $0.4417^{(1)}$ \\
\hline Median & 7.8 & 9.12 & \\
\hline \multicolumn{4}{|l|}{ Gleason score } \\
\hline$<7$ & $12(44.44)$ & $61(35.26)$ & $0.3934^{(2)}$ \\
\hline$\geq 7$ & $15(55.55)$ & $112(64.73)$ & \\
\hline \multicolumn{4}{|l|}{ Gleason predominant grade } \\
\hline \multicolumn{4}{|l|}{$<4$} \\
\hline 4 or 5 & $25(92.59)$ & $144(83.23)$ & $0.2653^{(2)}$ \\
\hline & $2(7.40)$ & $29(16.76)$ & \\
\hline \multicolumn{4}{|l|}{ Tumor extent } \\
\hline Mean \pm SD & $47.17 \pm 39.03$ & $35.49 \pm 37.04$ & $0.1190^{(1)}$ \\
\hline Median & 43 & 26 & \\
\hline Positive surgical margins & $10(37.03)$ & $71(41.04)$ & $0.8335^{(2)}$ \\
\hline Extraprostatic extension (pT3a) & $9(33.33)$ & $42(24.27)$ & $0.3447^{(2)}$ \\
\hline Seminal vesicle invasion (pT3b) & $3(11.11)$ & $24(13.87)$ & $>0.9999^{(2)}$ \\
\hline
\end{tabular}

SD = standard deviation; ${ }^{(1)}$ Mann-Whitney; ${ }^{(2)}$ Fisher exact-test.

proportion of 44/200 (22\%) men with PSA progression following surgery in our study is similar to $23.68 \%$ of Smith et al. (7).

In our series, there was no difference between the time to PSA progression in younger and older men. Our findings agree with Bauer et al. (5) and Catalona $\&$ Smith (6) but not with Smith et al. (7), Partin et al. (4) and Herold et al. (3)

Smith et al. (7) evaluated a surgically treated cohort of men 50 years or younger to determine whether disease recurred more frequently among them than those 51 to 69 years in the PSA era. Disease-free survival rates were compared using Kaplan-Meier and Cox regression techniques. The disease-free survival curves were significantly different (log-rank $p=0.010)$. Age remained a significant prognostic factor (Wald $\mathrm{p}=$ 0.033) in multivariate Cox regression analyses that controlled for race, clinical and pathological stage, and pretreatment PSA. The data suggested that patients in the PSA era who underwent radical prostatectomy and 
were aged 50 years or younger have a more favorable disease-free outcome compared to older men.

Partin et al. (4) determined from 100 men with clinically localized prostate cancer whether nuclear morphometry - when analyzed with initial stage, pathologic parameters, and age in a multivariate fashion - would predict time to disease progression. As univariate predictors, the variance of nuclear roundness, the mean of ellipticity, the Gleason score, age, and clinical stage were statistically significant predictors of disease progression when analyzed with Kaplan-Meier survival curves.

Herold et al. (3) sought to identify patient and treatment factors predictive of distant metastases in patients completing external beam radiotherapy. On univariate analysis age greater than 65 years, pretreatment prostate-specific antigen level, advanced stage, lower dose, and Gleason score 7 to 10 were statistically significant predictors of distant metastases at 5 years. Multivariate testing confirmed that age greater than 65 years, high pretreatment PSA level, lower radiation dose, and advanced stage were significant predictors of distant metastases.

Bauer et al. (5) evaluated age, race, prostatic phosphatase and nuclear grade with the established prognostic variables of pretreatment prostate specific antigen, postoperative Gleason sum and pathological stage. After multivariable Cox regression analysis using only statistically significant variables that predicted recurrence, they developed an equation that calculated the relative risk of recurrence. The model suggested that only race, preoperative prostate specific antigen, postoperative Gleason sum and pathological stage are important independent prognosticators of recurrence after radical prostatectomy for clinically localized prostate cancer.

Catalona \& Smith (6) used Kaplan-Meier product limit estimates to calculate 7-year cancer recurrence-free probabilities, prostate specific survival and cause survival (overall, and stratified by age, preoperative PSA, tumor grade and tumor stage. All predictors except clinical stage and age remained significant within the multivariate Cox proportional hazards models to determine clinical and pathological parameters that provided unique predictive information about cancer recurrence.
Concluding, our findings suggest that age alone do not influence the biological aggressiveness of prostate cancer.

\section{CONFLICT OF INTEREST}

None declared.

\section{REFERENCES}

1. Humphey PA: Prostate Pathology. Chicago, ASCP Press. 2003; p. 232.

2. Carter HB, Epstein JI, Partin AW: Influence of age and prostate-specific antigen on the chance of curable prostate cancer among men with nonpalpable disease. Urology. 1999; 53: 126-30.

3. Herold DM, Hanlon Al, Movsas B, Hanks GE: Agerelated prostate cancer metastases. Urology. 1998; 51: 985-90.

4. Partin AW, Steinberg GD, Pitcock RV, Wu L, Piantadosi S, Coffey DS, et al.: Use of nuclear morphometry, Gleason histologic scoring, clinical stage, and age to predict disease-free survival among patients with prostate cancer. Cancer. 1992; 70: 161-8.

5. Bauer JJ, Connelly RR, Seterhenn IA, Deausen J, Srivastava S, McLeod DG, et al.: Biostatistical modeling using traditional preoperative and pathological prognostic variables in the selection of men at high risk for disease recurrence after radical prostatectomy for prostate cancer. J Urol. 1998; 159: 929-33.

6. Catalona WJ, Smith DS: Cancer recurrence and survival rates after anatomic radical retropubic prostatectomy for prostate cancer: intermediate-term results. J Urol. 1998; 160: 2428-34.

7. Smith CV, Bauer JJ, Connelly RR, Seay T, Kane C, Foley J, et al.: Prostate cancer in men age 50 years or younger: a review of the Department of Defense Center for Prostate Disease Research multicenter prostate cancer database. J Urol. 2000; 164: 1964-7.

8. Mostofi, FK, Price EB Jr: Tumors of the Male Genital System, Atlas of Tumor Pathology, Second Series, Fascicle 8. Washington DC, Armed Forces Institute of Pathology. 1973; pp. 202-17.

9. Gleason DF, Mellinger GT; Veterans Administration Cooperative Urological Research Group: Prediction of prognosis for prostatic adenocarcinoma by combined histological grading and clinical staging. 1974. J Urol. 2002; 167: 953-8; discussion 959. 


\section{AGE AND PATHOLOGIC FINDINGS IN PROSTATECTOMY}

10. Gleason DF: Histologic grading of prostate cancer: a perspective. Hum Pathol. 1992; 23: 273-9.

11. Bostwick DG, Montironi R: Evaluating radical prostatectomy specimens: therapeutic and prognostic importance. Virchows Arch. 1997; 430: 1-16.

12. International Union Against Cancer: Prostate. In: Sobin LH, Wittekind Ch (ed.), TNM Classification of Malignant Tumours, 6th ed. New York, Wiley-Liss. 2002; pp. 184-7.

13. Epstein JI, Carmichael M, Walsh PC: Adenocarcinoma of the prostate invading the seminal vesicle: definition and relation of tumor volume, grade and margins of resection to prognosis. J Urol. 1993; 149: 1040-5.

14. Billis A, Magna LA, Ferreira U: Correlation between tumor extent in radical prostatectomies and preoperative PSA, histological grade, surgical margins, and extraprostatic extension: application of a new practical method for tumor extent evaluation. Int Braz J Urol. 2003; 29: 113-20.

15. Carter BS, Beaty TH, Steinberg GD, Childs B, Walsh PC: Mendelian inheritance of familial prostate cancer. Proc Natl Acad Sci U S A. 1992; 89: 3367 71.
16. Amling CL, Bergstralh EJ, Blute ML, Slezak JM, Zincke H: Defining prostate specific antigen progression after radical prostatectomy: what is the most appropriate cut point? J Urol. 2001; 165: 1146-51.

17. Han M, Partin AW, Zahurak M, Piantadosi S, Epstein JI, Walsh PC: Biochemical (prostate specific antigen) recurrence probability following radical prostatectomy for clinically localized prostate cancer. J Urol. 2003; 169: 517-23.

18. Sofer M, Savoie M, Kim SS, Civantos F, Soloway MS: Biochemical and pathological predictors of the recurrence of prostatic adenocarcinoma with seminal vesicle invasion. J Urol. 2003; 169: 153-6.

19. Moul JW, Douglas TH, McCarthy WF, McLeod DG: Black race is an adverse prognostic factor for prostate cancer recurrence following radical prostatectomy in an equal access health care setting. J Urol. 1996; 155: 1667-73.

20. Andersson J, Ekman P, Egevad L, Hellstrom M: Relatively high risk of treatment failure after prostatectomy: tumour grade, histopathological stage and the preoperative serum PSA level are key prognosticators. Scand J Urol Nephrol. 2001; 35: 453-8.

Received: February 24, 2005

Accepted after revision: August 30, 2005

\author{
Correspondence address: \\ Dr. Athanase Billis \\ Dept de Anatomia Patológica, UNICAMP \\ Caixa Postal 6111 \\ Campinas, SP, 13084-971, Brazil \\ Fax: + 5519 3289-3897 \\ E-mail: athanase@fcm.unicamp.br
}

\section{EDITORIAL COMMENT}

The direct relation of age and life expectancy and the different biologic characteristics of adenocarcinoma of the prostate in younger men have led us to be more knowledgeable in this field. It was thought before that the adenocarcinoma of the prostate in younger men was more aggressive (1), however, recent studies admit that younger individuals present more probability of tumors in confined organs and a 
less possibility of rescission when submitted to radical prostatectomy $(2,3)$.

A study with a similar design relating prostate cancer and age, performed in our Institution (in press) demonstrated that the anatomopathologic characteristics of the surgical piece (Gleason score and pathologic state) were equivalent in men under and over 60 years old.

The authors with this article have demonstrated that up to now, age has not yet been confirmed as a prognostic factor in prostate cancer, the discussion remaining open.

\section{REFERENCES}

1. Silber I, McGavran MH: Adenocarcinoma of the prostate in men less than 56 years old: a study of 65 cases. J Urol. 1971; 105: 283-5.

2. Khan MA, Han M, Partin AW, Epstein JI, Walsh PC: Long-term cancer control of radical prostatectomy in men younger than 50 years of age: update 2003. Urology. 2003; 62: 86-91; discussion 91-2.

3. Freedland SJ, Presti JC Jr, Kane CJ, Aronson WJ, Terris MK, Dorey F, et al.: Do younger men have better biochemical outcomes after radical prostatectomy? Urology. 2004; 63: 518-22.

\section{Dr. Marcos F. Dall'Oglio}

Division of Urology

Federal University of Sao Paulo, UNIFESP

Sao Paulo, SP, Brazil

E-mail: marcosdallogliouro@terra.com.br 